\title{
Metodologias ativas no Curso DE ITALIANO DA UFBA: RELATO DE EXPERIÊNCIAS INOVADORAS
}

\section{Metodologie attive nel corso di italiano dell'UFBA: resoconto di esperienze innovative}

\section{Active Methodologies at UFBA's Course of Italian Language: Report of an Innovative Experience}

Jadirlete Lopes Cabral *

RESUMO: Este artigo é fruto de uma das etapas cumpridas durante o meu estágio pós doutoral junto ao Programa de Pós Graduação em Educação e Contemporaneidade (PPGEDUC/UNEB), em que desenvolvi estudos diretamente no Grupo de Pesquisa em Geotecnologias, Educação e Contemporaneidade/GEOTEC acerca do tema: "Experiências inovadoras no ensino do italiano: uma investigação teórico crítica da própria prática docente". É um trabalho de natureza exploratória e se propõe a fazer uma reflexão crítica sobre minha prática pedagógica compreendida no período de 2013 ao primeiro semestre de 2019, no âmbito do ensino da língua italiana mediado por tecnologias digitais. Para tanto, farei um breve relato da minha experiência a fim de que, paralelamente, eu possa dialogar com alguns autores que têm norteado o meu trabalho ao longo desses anos de pesquisa e de atuação docente: Freire (1996), Cortelazzo; Fiala; Piva Júnior; Panissom, Junqueira e Rodrigues (2018), Hetkoswski (2010), Santaella (2016), Lèvy (1999; 2003), Bacich (2016), Bakhtin (1979), Mill (2018). Por fim, trarei algumas proposições acerca do uso das tecnologias digitais na educação, pontuando a necessidade urgente de mudança de paradigma educacional no contexto do século XXI.

PALAVRAS-CHAVE: Tecnologias digitais; Ensino de línguas estrangeiras; Contemporaneidade.

ABSTRACT: Questo articolo è il frutto di una delle fasi svolte durante uno stage di post-dottorato presso il Programma Post-Laurea in Educazione e Contemporaneità

Universidade Federal da Bahia (UFBA) -

jadeca@ufba.br (Orcid: 0000-0002-9381-8172)

DOI: http://dx.doi.org/10.11606/issn.2238-8281.v0i40p31-43 
(PPGEDUC/UNEB), in cui ho sviluppato attività direttamente nel gruppo di ricerca in Geotecnologia, Educazione e Contemporaneità/GEOTEC sul tema: "Esperienze innovative nell'insegnamento dell'Italiano: un'indagine teorico-critica sulla pratica di insegnamento stessa". È un lavoro di natura esplorativa e si propone di fare una riflessione critica sulla mia pratica pedagogica dal 2013 al primo semestre del 2019, nell'ambito dell'insegnamento della lingua italiana mediato dalle tecnologie digitali. A questo fine, farò un breve resoconto della mia esperienza affinché, in parallelo, io possa dialogare con alcuni autori che hanno ispirato il mio lavoro in questi anni di ricerca e pratica nell'insegnamento: Freire (1996), Cortelazzo; Fiala; Piva Júnior; Panissom, Junqueira e Rodrigues (2018), Hetkoswski (2010), Santaella (2016), Lèvy (1999; 2003), Bacich (2016), Bakhtin (1979), Mill (2018). Infine, presenterò alcune proposte riguardanti l'uso delle tecnologie digitali nell'istruzione, evidenziando l'urgente necessità di un cambiamento nel paradigma educativo nel contesto del $21^{\circ}$ secolo.

PAROLE CHIAVE: Tecnologie digitali; Insegnamento delle lingue straniere; Contemporaneità.

ABSTRACT: This article is the result of one of the stages accomplished during my postdoctoral internship at the Postgraduate Program in Education and Contemporary (PPGEDUC / UNEB) in which I developed research directly in the Research Group in Geotechnologies, Education and Contemporary/GEOTEC on the theme: "Innovative experiences in teaching Italian: a critical theoretical investigation of the teaching practice itself". It is an exploratory work and it proposes to make a critical reflection on my pedagogical practice from 2013 to the first semester of 2019, in the context of teaching the Italian language mediated by digital technologies. I will make a brief report of my experience so that, in parallel, I can establish a dialogue with some authors who have guided my work throughout these years of research and teaching: Freire (1996), Cortelazzo; Fiala; Piva Júnior; Panissom, Junqueira and Rodrigues (2018), Hetkoswski (2010), Santaella (2016), Lèvy (1999; 2003), Bacich (2016), Bakhtin (1979), Mill (2018). Finally, I will bring some propositions about the use of digital technologies in education, highlighting the urgent need for a change in the educational paradigm in the context of the 21 st century.

KEYWORDS: Digital technologies; Foreign language teaching; Contemporaneity. 


\section{Contextualizando com a cibercultura}

Se levarmos em conta as grandes transformações no campo das tecnologias da informação e comunicação, ensinar no contexto do século XXI impõe ao professor novos desafios que o levam a refletir sobre os princípios norteadores da sua profissão: ensinar o quê? Para quem? Como? Em que contexto? Assim, abro meu texto, pontuando a necessidade de nos perguntarmos se aquilo que temos ensinado e a forma como o fazemos tem, com efeito, alcançado o perfil atual dos nossos alunos e se temos estabelecido com eles um pacto de comunicação eficaz.

Vivemos uma época de muito trânsito e vivências nos espaços virtuais; o que, inevitavelmente, culmina numa alteração das nossas relações interpessoais, na nossa visão de mundo, na noção de tempo e espaço, na concepção de mundo real e mundo virtual, agora não mais tão separados como se acreditava há algumas décadas. Santaella (2016) nos chama a atenção para o fato de que vivemos um período de convergência de recursos midiáticos e de modos comunicacionais. Consequentemente, cria-se um cenário de convergência social, cultural, global, cujo conceito vai ao encontro da descrição feita por Pierre Lèvy (1999) a respeito da sociedade contemporânea como uma sociedade conectada em rede, que busca se reconhecer e se fazer conhecer por meio das redes sociais, onde é possível dispor de diferentes mídias digitais como forma de expressão e de compartilhamento de saberes. Jenkins, citado em Contreras-Espinosa, afirma que:

A convergência não é apenas um processo tecnológico que une múltiplas funções dentro dos mesmos aparelhos. É um processo de transformação cultural no qual é possível identificar novos graus de participação dos usuários, novas ligações com os conteúdos, novas orientações, novas leis de direitos autorais e novos meios de aferir audiência. (JENKINS apud CONTRERAS, 2018, p. 130)

Por termos à nossa disposição infinitas possibilidades de recursos e de informação, a teia de conhecimentos é construída em coautoria, colaborativamente, num processo de apropriação e de transformação do já existente para criação do novo, do autenticamente criativo, de forma multidirecional ${ }^{1}$ e à velocidade da propagação da comunicação pelas mídias digitais. Sem dúvida alguma, estamos diante de um novo cenário de mundo, em que podemos observar uma vasta gama de caminhos para a inovação das velhas práticas, o que faz da discussão sobre a convergência ${ }^{2}$ educativa e informativa uma necessidade premente.

Não obstante todas essas transformações sociais, culturais e de popularização de aparatos tecnológicos até mesmo em contexto educacional, é possível ainda notar a adoção de velhas práticas em que a figura do professor continua no centro do processo de ensino e de aprendiza-

1 O conceito que trago para teias de conhecimento construídas de forma multidirecional está respaldada pelo conceito de Cibercultura e de Inteligência Coletiva defendidos por Pierre Lèvy (1999; 2003), segundo o qual as formas de saberes estão distribuídas em todas as partes, proporcionando "[...] uma sinergia entre competências, [...] a ativação de modos de cooperação flexíveis e transversais [...] opõem-se à separação estanque entre as atividades, às compartimentalizações, à opacidade da organização social" (1999, p.31)

2 Destaco nesse contexto a necessidade de uma intensificação das discussões em torno do tema convergência educativa e informativa, fazendo alusão à abertura proporcionada pelas Portarias no 4.059/2004 e 2.117/2019 que dispõem sobre a implementação das tecnologias digitais nos processos de ensino e de aprendizagem e sobre o percentual de carga horária na modalidade EAD para alguns cursos presenciais da graduação. 
gem. Cortelazzo e seus coautores (2018) trazem importantes reflexões acerca da implementação e da importância da educação mediada por tecnologias digitais hoje em dia. Fazendo uma reflexão do desenvolvimento histórico na educação brasileira, ele afirma que:

A influência deste modelo tradicional de educação, embora tenha sido amplamente combatida ao longo do século XX, continuou sendo exercida de forma significativa no cenário educativo e seus resquícios podem ainda ser sentidos nos dias atuais; apesar de todos os discursos teoricamente renovadores pelos quais vêm passando nossos sistemas educacionais. (CORTELAZZO et al., 2018, p. 44)

Desse modo, os recursos tecnológicos, tais como notebook, datashow, tablets e similares, são ainda (e infelizmente), em alguns contextos, meros instrumentos utilizados, muitas vezes, sem um planejamento crítico do porquê do seu uso e de quais são as suas implicações pedagógicas no ambiente da sala de aula e no processo formativo dos discentes.

\section{O início de tudo. As metodologias ativas como abordagem}

Foi pensando nessas questões que me propus a refletir sobre qual seria a melhor forma de interagir com meus alunos de modo a despertá-los para um caminhar autônomo no seu processo de aprendizagem. Vendo nas tecnologias digitais uma forma de potencializar esse processo, passei a me interessar pela modalidade híbrida de ensino, no início de 2013, a partir de um convite para colaboração em pesquisa feito pelo professor Rafael Ferreira, da Universidade

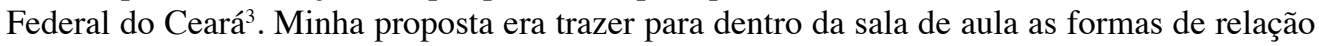
com as tecnologias digitais e, num sentido mais amplo, o conceito de cibercultura vivido fora do ambiente acadêmico. No mesmo ano, decidi formar um grupo de pesquisa intitulado Ensino e Aprendizagem de Línguas com Tecnologias Digitais/CNPq, em parceria com a professora e colega Jael Glauce da Fonseca. Nosso objetivo era - e ainda é - unir o ensino e a aprendizagem de línguas, inclusive libras e português como língua estrangeira, às tecnologias digitais, com o intuito de despertar o Instituto de Letras da Universidade Federal da Bahia, doravante UFBA, para essa modalidade de Educação Tecnológica voltada para o ensino e aprendizagem de línguas e para a formação de professores. Atualmente, a professora Cecilia Aguirre de Souza/ UFBA e eu somos as líderes do grupo e contamos com uma equipe multidisciplinar formada por competentes professores, representantes das diferentes línguas e linguagens, engajados na pesquisa das Tecnologias Digitais da Informação e da Comunicação e na implementação dessa modalidade educacional no nosso Instituto.

Ao mesmo tempo em que lia referências teóricas sobre Cibercultura (LÈVY, 1999; 2003; dentre outros autores) e sobre os desafios de educar na era digital, fui percebendo com mais facilidade que eu estava diante de um público diferenciado, isto é, com diferentes níveis de letramento digital: alguns bastante familiarizados com as tecnologias apenas no contexto social, mas bastante resistentes ao uso dessas ferramentas no contexto educativo. Outros, por questões ideológicas e em menor número, avessos a qualquer proposta que conectasse ensino 
e tecnologia. Constatação demasiado estranha para mim, pois eu não via muito sentido em não enxergar os aparatos tecnológicos como instrumentos potencializadores das nossas habilidades e competências, quando, fora do contexto acadêmico, são essas mesmas habilidades e competências, fruto das nossas vivências pessoais, que colocamos em ação nos ambientes virtuais com o intuito de contribuir para o bem da coletividade à qual pertencemos. Organizar-se em comunidades virtuais constitui uma das características sociais do século XXI.

Pierre Lévy (2003) chama esses processos Inteligência Coletiva, isto é, formas de relações humanas em comunidades virtuais em que o saber, quando devidamente coordenado e orientado pelos recursos tecnológicos, potencializa as competências individuais em prol da coletividade. Ou seja: aquele saber, antes pulverizado em diferentes partes, reúne-se num mesmo espaço virtual, desterritorializado, para atender às demandas específicas de uma mesma comunidade virtual. Esse modo de compartilhar o conhecimento, potencializado pelo uso do celular, por exemplo, abre espaço para uma aprendizagem ubíqua, o que é, do ponto de vista de uma pedagogia emancipatória, um vasto e rico campo de possibilidades a serem exploradas.

Assim, respaldada pelos conceitos e definições de habilidades e competências da Base Nacional Comum Curricular, sobretudo no que se refere à capacidade de interagir em redes de forma ética e solidária valorizando e compartilhando saberes e experiências, ao exercício da empatia e do diálogo em redes sociais, à capacidade de utilizar diferentes linguagens no ato de comunicação, dentre outros, passei a priorizar nas aulas presenciais e a distância as diferentes formas de metodologias ativas aliadas aos recursos digitais. Embora não sejam novidade no campo da pedagogia, as metodologias ativas são fundamentais para a devida compreensão da modalidade híbrida de ensino, pois nela o professor cria as condições pedagógicas necessárias para impelir os alunos a saírem da zona de conforto e a experimentarem sensações que os levem a assumir o seu papel autônomo diante do processo de construção da sua própria aprendizagem, nos moldes de uma aprendizagem emancipatória e libertadora, defendida por Paulo Freire (1992).

Fazendo um breve percurso sobre o tema, desde o Movimento da Escola Nova, iniciado no final do século XIX, mas difundido nas primeiras décadas do século XX, a educação brasileira tem militado pela renovação do modelo tecnicista para um modelo progressista, em que o aluno é colocado no centro do processo de aprendizagem e o professor, como orientador desse processo. Embora as discussões sobre o assunto sejam abundantes, em todos esses anos podemos observar que poucos aspectos mudaram, de fato, na educação. Com a ampla difusão das tecnologias digitais em contextos acadêmicos, sobretudo com a popularização de smartphones entre os alunos ${ }^{4}$, as discussões acerca das metodologias ativas voltaram a ocupar o cenário da educação no Brasil. Por esse modelo, há uma inversão dos papéis do professor e do aluno. Cortelazzo et al. (2018, p. 95), citando Prensky, nos apresentam alguns parâmetros que nos auxiliam a ter um melhor entendimento dessas novas configurações de papéis do profes-

4 Fontes estatísticas: IBGE - PESQUISA NACIONAL POR AMOSTRAS DE DOMICÍLIO CONTÍNUAS - PNAD CONTÍNUAS. Disponível em: https://biblioteca.ibge.gov.br/visualizacao/livros/liv101543.pdf, acesso em: 06/08/2020. SUPERINTENDÊNCIA DE ENSINO A DISTÂNCIA/UFBA. Disponível em: https://sead.ufba.br/sites/ sead.ufba.br/files/relatorio_graduacao.pdf . Acesso em: 06/08/2020. 
sor e do aluno no contexto de uma pedagogia ativa. De acordo com essa nova configuração, o professor: a) atua fazendo mais perguntas e expondo menos seus pontos de vista; b) sugere tópicos para discussão e os instrumentos necessários para a realização do trabalho; c) aprende tecnologia com os estudantes; d) avalia as soluções e respostas dos alunos, examinando a qualidade e o rigor. Quanto ao papel do aluno: a) não toma notas, mas procura e acha; b) pesquisa e encontra soluções; c) aprende sobre qualidade e rigor com o professor; d) refina e melhora as respostas adicionando rigor, contexto e qualidade.

Observa-se, no primeiro item, que nesse novo modelo o professor deve motivar o aluno fazendo perguntas adequadas; o que se aproxima do princípio da Maiêutica Socrática. Os autores seguem afirmando que

[esse método] pressupõe que a verdade está latente em todo ser humano, podendo aflorar aos poucos à medida que se responde a uma série de perguntas, ou seja, o ponto central está em saber fazer as perguntas certas. (CORTELAZZO et al., 2018, p. 96)

Por essas e outras razões, a tecnologia jamais ocupará o lugar do professor, substituindo-o. Ele faz e sempre fará essa ponte entre o humano e o maquínico; entre o criar e o executar. $\mathrm{O}$ papel do professor torna-se fundamental nesse contexto de infinitas possibilidades de saber, de infinitos conteúdos abertos. É ele quem tem o olhar crítico do gerenciamento dos mapas conceituais e da formação de trilhas de aprendizagem em redes, que se tornaram mais complexas no contexto da cibercultura. É ele o responsável por pensar a melhor metodologia ativa ou não a ser adotada para determinado percurso formativo e, por fim, é quem identifica as deficiências e possibilidades de cada estudante, sendo capaz de intervir com soluções pontuais, criativas e práticas.

\section{Vivenciando as metodologias ativas em contextos híbridos: algumas reflexões}

Após essas breves considerações, retomo a discussão acerca da minha experiência com as metodologias ativas aliadas à modalidade híbrida nas minhas aulas presenciais e a distância. Ao ver nos aparatos tecnológicos a possibilidade de concretização de um novo fazer pedagógico, comecei a implementar nas minhas aulas atividades mediadas por aplicativos, programas, plataformas e fui coletando experiências, desde aquelas ligadas ao funcionamento técnico até aquelas das reações dos participantes. Inicialmente, vivi as angústias próprias de quem se aventura a implementar recursos absolutamente novos, adaptando-os a novas estratégias e técnicas de ensino, mesmo diante das reais dificuldades técnicas que esses instrumentos oferecem à primeira vista. Após o período de isolamento social decorrente da pandemia provocada pela Covid-19, eu me sinto muito mais à vontade para falar dessas angústias, pelo fato de que, com a quarentena, todos fomos surpreendidos e forçados a esse tipo de confrontamento. Aliás, tudo o que é novo revela, por um lado, nossas fragilidades, mas também nos desperta 
paralelamente para o poder de criar, de inovar e de ressignificar nossa realidade. Não quero, contudo, fazer nenhuma apologia à dor, fruto de um ato de violência, mas a defendo como fruto de um processo evolutivo, em que somos colocados à prova e impelidos a sair da nossa zona de conforto. Precisamos conceber as dificuldades como oportunidades de superação sempre.

Em sentido figurado, vivi angústias associadas desde a simples montagem de slides com imagens cortadas e redimensionadas até a elaboração de vídeo aulas e de transmissão via streaming em redes sociais. Foram horas investidas em preparação de aulas, de atividades lúdicas com tecnologias digitais, games, etc. tudo isso com o intuito de inovar e de envolver meus alunos para então ajudá-los a ter a real noção dos seus percursos de aprendizagem, da seleção crítica daquilo que poderia ser ou não útil como informação e das formas possíveis de trabalho coletivo e colaborativo.

Um período muito profícuo, no sentido de diversificação de estratégias e técnicas de ensino, foi durante a coordenação do Programa de Proficiência em Língua Italiana para Alunos e Servidores da UFBA (Proemit) em 2015, com a colaboração do monitor Robson Leite dos Santos. Naquela época, organizamos cursos de formação de professores no contexto do Programa de Proficiência de Línguas Estrangeiras para Alunos e Servidores da UFBA (PROFICI/UFBA), em parceria com a equipe técnica da Superintendência de Tecnologia da Informação / STI, trazendo excelentes resultados para todo o Programa e, dessa forma, colaborando para a sua premiação em avaliação nacional de cursos de idiomas e internacionalização no mesmo ano.

Nos anos que se sucederam até o primeiro semestre de 2019, graças ao apoio de monitores bolsistas selecionados por meio de projetos de monitoria, publicados em editais internos como, por exemplo, os de $\mathrm{n}^{\mathrm{o}}$ 001/2017, e 001/2019, foi possível dar continuidade à proposta híbrida de ensino, dando especial atenção ao processo de investigação do funcionamento dos ambientes virtuais de aprendizagem, das redes sociais adotadas com fins pedagógicos, ao uso de aparatos tecnológicos nas aulas presenciais e a distância.

No afã de querer diversificar o máximo possível as possibilidades tecnológicas no contexto das aulas de italiano, inicialmente constatei de imediato a inviabilidade na utilização de tantos recursos que a cada instante se renovavam. A carga horária do curso somada ao programa bastante extenso não permitia reservar um tempo extra para ambientação e familiarização com os diferentes recursos tecnológicos adotados em diferentes momentos do curso. No mundo da tecnologia, tudo é muito fugaz e isso provoca a dilacerante angústia de que estamos sempre um passo atrás em relação às inovações desses instrumentos. Sem mencionar, outrossim, o estresse gerado na condução das atividades, que pareciam muito pulverizadas, ou talvez em posição menos relevante no processo de ensino e aprendizagem, em meio a tantos aparatos tecnológicos.

Não era esse o caminho. $\mathrm{O}$ foco do professor não pode estar depositado na instrumentalização dos recursos tecnológicos em si. Ensinar com tecnologias é muito mais do que fazer um simples uso desses aparatos. Ensinar com tecnologias digitais é um conceito, uma filosofia de 
trabalho. Se voltarmos na história e buscarmos na filosofia socrática o entendimento do que é tecnologia, concluiremos que todo e qualquer instrumento de que fazemos uso para intervir na nossa realidade para, em seguida, transformá-la, é tecnologia. Em termos etimológicos, Mill e Bertoldo (2018) remontam ao conceito clássico para trazer a definição da palavra tecnologia como derivada da palavra techné, ligada ao conceito de arte. Vejamos o que dizem os autores:

Tecnologia, técnica e arte têm raíz etimológica comum derivada da palavra grega

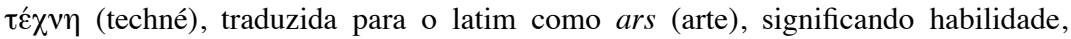
destreza ou ofício e qualquer atividade que siga regras ('padrões de meios-fins'), capaz de transformar o mundo natural em um mundo artificial. (MILLe BERTOLDO, 2018, p. 598)

Dito em outras palavras, tecnologia é a capacidade humana inventiva, criativa, que une as habilidades inerentes a cada um de nós a um processo cognitivo ordenado, sistemático, consciente ou não, experienciado ou não. Essa compreensão da techné como algo que transcende o sentido material, do aparato tecnológico em si, vem corroborado pelo grupo GEOTEC, nas palavras de Hetkowski como:

Tecnologia é um processo humano criativo caracterizado a partir do entendimento, vivências e práticas inventivas para a realização de atividades cotidianas e de adaptação do ser humano no mundo. Portanto, o pensamento é a fonte matriz da técnica para a compreensão, transformação e superação de determinada situação existente. (2010, p. 6)

Assim, ao ampliar a minha compreensão de que o uso dos recursos tecnológicos emanava das demandas naturais de um contexto de sala de aula (como fotografar as anotações da lousa, consultar os conteúdos ministrados na internet etc.) e que tais recursos já vinham sendo usados pelos alunos como instrumentos potencializadores da aprendizagem (reuniões para a realização de trabalho em grupo; criação de comunidades para compartilhamento de informações sobre cursos e aplicativos úteis à aprendizagem etc.), decidi inverter o quadro de análise e colocar meu olhar investigativo no processo de mediação na condução das aulas, nos caminhos seguidos por cada aluno rumo à construção da aprendizagem mediadas pelas tecnologias digitais e nos resultados obtidos. Na ordem da investigação, a análise do desenvolvimento precede a dos resultados. Não é um processo simples, pois exige do professor uma atenção minuciosa e praticamente personalizada, sobretudo quando a proposta de trabalho é observar o processo de vivências de aprendizagem focado no aprendente. E quando se fala, então, de coletivismo e de colaborativismo, devemos voltar nosso olhar principalmente para o indivíduo, que também é latência e potência. Embora a subjetividade pareça tão diluída nesse mundo de interconectividade e de formação de redes de interação, sempre se fará necessário atentar para o desempenho que cada aluno possui na construção das suas trilhas de aprendizagem, pois é nesse processo de observação que o professor poderá intervir estrategicamente para ajudar o discente a reconfigurar a sua itinerância. 
Comecei, então, a estruturar o meu trabalho partindo da diagnose dos meus alunos: quem eram? Quais eram as suas reais motivações para aprenderem italiano? Quanto eram letrados tecnologicamente? Quais os recursos tecnológicos de que dispunham para estudar? Quantas horas por dia dedicavam ou dedicariam à aprendizagem da língua? Foram perguntas iniciais que me ajudaram a conhecê-los para, em seguida, pensar de que forma eu poderia auxiliá-los na aprendizagem do italiano.

A partir disso, objetivando firmar um pacto de trabalho colaborativo previamente discutido com os alunos, propus aplicar um questionário diagnose no início de cada semestre e outro, de avaliação do percurso seguido, ao final do curso. Era a maneira de afirmar: esse trabalho não pode ser construído somente por mim; conto com vocês. A proposta era envolver todos eles no processo, fazendo-os se sentirem parte, corresponsáveis pela construção de todo o trabalho. Sem um adequado fortalecimento do sentimento de pertença, é muito difícil construir o conceito de autonomia, que é um dos quatro eixos conceituais (autonomia, protagonismo, empoderamento e gestão compartilhada) estruturados no documento "Novos Mapas Conceituais" do projeto Cultura Viva ${ }^{5}$. A ele também vem associado o conceito de protagonismo, que significa o empenho pessoal para apresentar propostas de soluções originais aos problemas colocados para a coletividade; ao conceito de empoderamento, definido em sentido mais amplo que o conceito de autonomia como sendo o estabelecimento de oportunidades de atuação dos sujeitos envolvidos num processo de disputa, em diferentes espaços, com o fim de alcançar representatividade política e visibilidade pública; e, por fim, ao conceito de gestão em rede, em que se privilegia a gestão compartilhada, corresponsável, diluída entre os sujeitos atuantes. Esses eixos orientam o professor na sua forma de condução dos trabalhos mediados pelas tecnologias digitais, de modo a propiciar o desenvolvimento das competências e habilidades de cada aluno a partir de estratégias e de atividades específicas.

Como acontece em todas as turmas em diferentes instituições de ensino, os alunos que chegam à sala de aula para aprenderem italiano foram impulsionados por diferentes motivos. A depender do quanto estejam dispostos a superar os desafios comuns a todo processo de aprendizagem e a serem confrontados pelas dificuldades apresentadas, muitos acabam por desistir no meio do caminho. Como referido acima, a aprendizagem remota exige muito mais autonomia por parte do aluno, além de rigorosa disciplina e muita perseverança. Por isso, a práxis pedagógica precisa prever um aluno que atua, que aprende fazendo.

Assim, voltando à minha experiência em sala de aula, a partir da sondagem pelo questionário diagnose, que visava a mapear o perfil digital dos alunos, a maioria deles escolheu o WhatsApp como interface ideal a ser adotada, em virtude da sua praticidade, acessibilidade e da velocidade com que se pode interagir.

Uma vez conhecidas as potencialidades do aplicativo, passei a utilizá-lo como recurso complementar às aulas presenciais, no intuito de oferecer aos discentes um contato diário com

5 O Programa Cultura Viva é uma ação do governo federal desde 2004, mas sancionado como Política de Estado a partir da Lei 13.018. O Programa visa a simplificar e desburocratizar os processos de reconhecimento, prestação de contas e repasse de verbas para organizações culturais. PROGRAMA CULTURA VIVA: Rede de Incentivo e Disseminação de Iniciativas Culturais. Disponível em: http://culturaviva.gov.br/saiba-mais/, acesso em 26/08/2020. 
a língua italiana, por meio de atividades breves e bastante pontuais, de modo que eles eram motivados a falarem de si ou do seu quotidiano, transformando aquele espaço virtual em uma pequena comunidade para a troca de informações e de experiências em língua italiana. Nessa forma de interação ubíqua, é possível observar novas formas de construções discursivas tanto no sentido das transformações dos papéis dos sujeitos envolvidos no ato comunicativo quanto do ponto de vista das múltiplas formas de comunicação: fotos, vídeos, textos, podcasts, emojis etc. Esses elementos constituem um terreno muito fértil no âmbito do ensino de línguas, o que nos impulsiona para uma criteriosa exploração dos mesmos. Os conceitos de dialogismo e polifonia bakhtinianos nos oferecem um excelente suporte para a compreensão desses novos atos discursivos, uma vez que emergem como ato enunciativo oriundo de múltiplas vozes sociais, em diferentes espaços físicos constituídos de culturas e crenças diversas. Cada sujeito falante é um ser de comunicação em si em contínuo estado de potência. Pesce e Hessel afirmam que

[...] os ambientes digitais e em rede, quando explorados pelos formadores com base na dialogia digital, podem vir a redimensionar os conceitos de tempo e espaço da sala de aula, ampliando a perspectiva da alteridade em cada formando e o auxiliando na construção de um conhecimento contextualizado e ressignificado. Ao fazê-lo, situa os alunos como protagonistas da construção dos seus saberes. (2018, p. 168)

Entretanto, alguns pontos negativos no uso do WhatsApp merecem ser comentados. Normalmente as turmas de italiano básico são bem numerosas, somando uma média de 30 a 40 alunos e, às vezes, até mais. Por isso, algumas vezes precisei organizar o grupo em subgrupos de trabalhos e isso reduzia a praticidade do processo, haja vista que não possui a mesma estrutura organizacional que a plataforma Moodle, por exemplo. Outra desvantagem refere-se à invasão de privacidade do professor. Isso significa dizer que as mensagens para esclarecimento de dúvidas chegavam até mesmo nos finais de semana ou de madrugada. E aqui abro um parêntese para sinalizar a necessidade urgente de se incluir entre as discussões acerca do ensino remoto um espaço para uma discussão atenta sobre a carga horária de trabalho do professor nessa modalidade de ensino. Ademais, hoje em dia, discute-se bastante sobre netiqueta e já não é mais um tabu impor limites para se estabelecer um protocolo de convivência no mundo virtual. Todavia, há cinco anos pelo menos, estávamos ainda no início dessa nova forma de nos relacionarmos. Por se tratar de uma situação nova, era natural passar por essa experiência. Algumas regras de convivência foram construídas durante o processo de interação e de forma conjunta, como solução para pequenos conflitos ou desconfortos. Por isso, passei a utilizar o espaço da descrição do grupo para o estabelecimento de regras de convivência e de realização das tarefas, assim como para as informações principais: local e horário das aulas, início e fim do curso, conteúdos, metodologias, estratégias etc. Tal medida ajudou-nos a organizar melhor o andamento dos trabalhos.

Dentre as várias experiências obtidas, o WhatsApp funcionou muito bem com as listas colaborativas, em que abordamos conteúdos gramaticais e lexicais, e também na realização de 
aulas invertidas. Nessas, eram postadas atividades que serviam como discussão preliminar do conteúdo a ser melhor desenvolvido em aula presencial, com base no compartilhamento das vivências, habilidades e competências individuais, de modo que o WhatsApp se revelou como uma excelente interface para trabalhar conteúdos lexicais, gramaticais, produção oral, produção escrita, compreensão oral, compreensão escrita, e para abordagem e discussão de temas interculturais.

Ademais, foi enriquecedor trabalhar a pronúncia, que é um aspecto da língua desafiador no início do curso, por meio de campeonatos de trava-língua e listas colaborativas de músicas pelo Spotify. Propor a interação com falantes nativos por meio de tandem virtual, via Skype e presencial também trouxe resultados satisfatórios que merecem continuidade nas minhas novas propostas de trabalho híbrido.

As abordagens, métodos e técnicas utilizados, a partir de ações criativas mediadas pelos poucos, e às vezes precários, recursos digitais disponíveis, propiciaram um ambiente motivador, inclusivo, colaborativo, capaz de tornar o aluno mais participativo e responsável pelo seu processo de aprendizagem e também mais crítico em relação aos caminhos escolhidos e trilhados para se chegar aos resultados almejados.

Prova disso foi a produção de alguns excelentes trabalhos de conclusão de curso, resultado criativo de projetos em equipes, mediados por um recurso tecnológico de livre escolha de cada grupo. Com base nesse aprendizado natural e orgânico, os alunos se viam encorajados à autoavaliação através de um questionário para mapeamento dos resultados obtidos. Mesmo em se tratando daqueles que se atribuíam notas inferiores àquelas pretendidas, o faziam com propriedade, mediante argumentações precisas do porquê daquela avaliação.

\section{Algumas proposições e considerações finais}

Neste trabalho, apresentei o recorte de um relato de experiências inovadoras no ensino de aquisição da língua italiana no período compreendido entre 2013 e o primeiro semestre de 2019 , trazendo discussões com alguns autores, tais como: Freire (1996), Cortelazzo et al. (2018), Hetkoswski (2010), Santaella (2016), Lèvy (1999; 2003), Bacich (2016), Bakhtin (1979), Mill (2018), que têm norteado a minha pesquisa ao longo desses anos bem como têm me ajudado a alcançar uma compreensão mais ampla do que seja o ensino mediado por tecnologias digitais no contexto do século XXI.

Já se tornou indiscutível a necessidade de se adotarem os recursos tecnológicos como instrumentos potencializadores do ensino e da aprendizagem. Se compararmos com algumas décadas passadas, podemos afirmar que vivemos atualmente uma fase na história da humanidade em que as informações estão literalmente mais ao alcance das nossas mãos: podemos acessar os acervos de famosos museus em todo o mundo sem sair de casa; com uma rápida busca na internet, podemos ter acesso a informações variadas, à disposição de boa parte da população no Brasil e no mundo. É um momento em que aprendemos fazendo, buscando, compartilhando 
conhecimentos. Muitos dos nossos alunos já nasceram nessa modalidade ativa de construção de saberes. Todo esse contexto social, histórico e antropológico reflete uma cultura cibernética, uma cibercultura, responsável por configurar toda uma geração tecnologicamente ativa, conectada no plano físico, emocional e intelectual, não só no que se refere às suas relações interpessoais como também, e principalmente, aos diversos modos de comunicação e acesso às informações. Se quisermos "falar a mesma língua" dos nossos alunos, nossa práxis docente deve acompanhar essas transformações para então adotarmos formas de ensino personalizadas. Com o tempo e a prática, veremos que as tecnologias aplicadas em contextos educacionais nos ajudarão a ter tempo para pensar e estruturar esse ensino personalizado, contextualizado, geotecnológico. Nesse contexto, faz-se necessário discutir e incentivar a elaboração de materiais didáticos personalizados, que atendam às demandas do lugar das vivências, de onde emanam as ricas experiências de ensino e aprendizagem.

Tudo isso envolve um percurso ainda a ser percorrido obrigatoriamente até que cheguemos a um nível ideal de maturidade acadêmica não só por parte dos alunos, mas também da parte do professor, para então investir numa modalidade de ensino totalmente a distância no contexto da UFBA. Há questões de infraestrutura a serem debatidas e solucionadas, há caminhos de resistências à inovação a serem revistos e paira ainda um paternalismo no ensino que precisa ser vencido, a fim de que o aluno, finalmente, possa perceber a urgente apropriação da construção do seu percurso formativo.

Para tanto, precisamos nos convencer de que as formas de interações sociais e as formas de comunicação mudaram. É necessário adequar nosso discurso ao discurso dos nossos alunos, observando atentamente os tipos e os modos de funcionamento dos meios de comunicação atuais.

As tecnologias digitais pressupõem dos sujeitos uma postura ativa, orgânica e viva. A aprendizagem nesse contexto encontra-se em contínuo estado de latência e potência. Cabe a nós professores adotar as formas adequadas e oportunas de intervenção por meio de um olhar atento às oportunidades, a um criterioso planejamento do curso, a uma acurada construção das trilhas de aprendizagem, às competências e habilidades que almejamos formar nos nossos alunos.

Por fim, é necessário observarmos, nesse contexto de ensino emergencial a que fomos obrigados pela pandemia, as oportunidades de inovação, aqui entendida como processo humano criativo, imaterial, capaz de suscitar reflexões a respeito de formas novas de interação social, de ensino e de aprendizagem mediados pelas tecnologias digitais. Poderemos, deste modo, reconfigurar nossas práticas docentes e ousar na criação e apropriação de nossos próprios métodos com vistas à elaboração de materiais didáticos digitais personalizados, que possibilitem um percurso formativo contextualizado emancipatório, multidirecional e colaborativo para o ensino da língua italiana. 


\section{Referências}

BACICH,L.Ensino Híbrido: Proposta de formação de professores para uso integrado das tecnologias digitais nas ações de ensino e aprendizagem. Anais do Workshop de Informática na Escola, [S.1.], p. 679, nov. 2016. ISSN 2316-6541. Disponível em: <https://www.br-ie.org/pub/index.php/wie/article/ view/6875/4753 > . Acesso em: 06/08/2020. doi:http://dx.doi.org/10.5753/cbie.wie.2016.679

BAKHTIN, M. Estética da criação verbal. Trad. M.E.G. Pereira. $2^{a}$ ed. São Paulo: Martins Fontes, 1979.

BERTOLDO, H. L.; MILL, D. Tecnologia. In: MILL, D. (org.). Dicionário crítico de educação e tecnologias e de educação a distância. Campinas, São Paulo: Papirus, 2018.

BRASIL.: Seminário Internacional do Programa Cultura Viva: Novos Mapas Conceituais. Ministério da Cultura, Pirenópolis, 2009.

BRASIL. Secretaria de Educação Superior. PORTARIA N ${ }^{\circ} 4.059$, DE 10 DE DEZEMBRO DE 2004, publicada em DOU, de 13/12/2004, Seção 1, p. 34, <http://portal.mec.gov.br/sesu/arquivos/pdf/nova/ acs_portaria4059.pdf>. Acesso em: 29/08/2020.

BRASIL. Ministério da Educação. PORTARIA N ${ }^{\circ}$ 2.117, DE 6 DE DEZEMBRO DE 2019. Dispõe sobre a oferta de carga horária na modalidade de Ensino a Distância - EaD em cursos de graduação presenciais ofertados por Instituições de Educação Superior - IES pertencentes ao Sistema Federal de Ensino. Diário Oficial da União, Brasília, DF, seção 1, p. 131, dez. 2019. Disponível em: <https:// www.in.gov.br/en/web/dou/-/portaria-n-2.117-de-6-de-dezembro-de-2019-232670913>. Acesso em: 29/08/2020.

CONTRERAS-ESPINOSA, R. S. Convergência midiática e educação. In: MILL, D. (org.). Dicionário crítico de educação e tecnologias e de educação a distância. Campinas, São Paulo: Papirus, 2018.

CORTELAZZO, A.; FIALA, D. A. S.; PIVA JR., D.; PANISSOM, L.; JUNQUEIRA, M. R.; RODRIGUES, B. Metodologias ativas e personalizadas de aprendizagem: para refinar seu cardápio metodológico. RJ: Alta Books, 2018, 224 p.

FREIRE, P. Pedagogia da esperança. 25a ed. São Paulo: Edufscar, 1992. ISBN: 978-85-7753-177-6 e Terra, 1996 .

. Pedagogia da autonomia: Saberes necessários à prática educativa. 33 ed. São Paulo: Paz

LÉVY, P. Cibercultura. São Paulo: Ed. 34, 1999

. A inteligência coletiva: por uma antropologia do ciberespaço. São Paulo: Loyola, 2003

HETKOWSKI, T. M. Geotecnologia: como explorar educação cartográfica com as novas gerações? In: XV Encontro Nacional de Didática e Práticas de Ensino (ENDIPE), 2010, Belo Horizonte. Anais... Belo Horizonte, MG: UFMG, 2010.

LIMA Jr. A. S. de; HETKOWSKI, T. M. Educação e Contemporaneidade: por uma abordagem histórico-antropológica da tecnologia e da práxis humana como fundamento dos processos formativos e educacionais. In. LIMA Jr. A. S. de; HETKOWSKI, T. M. (Orgs). Educação e Contemporaneidade: desafios para a pesquisa e a pós-graduação. Rio de Janeiro: Quarteto, 2006 241-272.

MILL, D. (Org.). Dicionário crítico de educação e tecnologias e de educação a distância. Campinas, SP: Papirus, 2018.

PESCE, L.; HESSEL, A. Dialogia digital. In: MILL, D. (org.). Dicionário crítico de educação e tecnologias e de educação a distância. Campinas, São Paulo: Papirus, 2018.

SANTAELLA, L. Adeus às fronteiras entre natureza e cultura. Revista Observatório Itaú Cultural: OIC. - N. 19 (nov. 2015/maio 2016). - São Paulo: Itaú Cultural, 2007-ISSN 1981-125X (versão impressa)

Recebido em: 07/09/2020

Aprovado em: 17/12/2020 